\title{
AN EXPERIMENTAL INVESTIGATION OF TERNARY BLENDED HYBRID FIBER REINFORCED CONCRETE (MK: FA: GGBS): STEEL \& POLYPROPYLENE FIBERS
}

\author{
K. Nagaraja \\ Research Scholar, Jawaharlal Nehru Technological University, Ananthapuramu, India \\ H. Sudarshan Rao \\ Director, IIIT, RK Valley Campus, \\ Rajiv Gandhi University of Knowledge Technologies, Andhra Pradesh, India
}

\begin{abstract}
In recent times, the world is taking into a part of challenging construction by using hard structures and high strength concretes. The proposed procedure deals with the experimental examination to find the mechanical properties of ternary blended concrete with hybrid fibers. Utilizations of mineral admixtures, such as, Fly Ash (FA), Metakaolin (MK) and Ground Granulated Blast Furnace Slag (GGBS) are efficient to increase the strength and make sturdy for high strength concrete. Mechanical behavior of ternary blended concrete is prepared by high rates of ternary mixes like $M K, F A$, GGBS (10\%-30\%) and hybrid fibers (steel and polypropylene) with different volume parts (Steel:0.5-2\%; PP:0.1-0.5\%) are explored. The specimens are set up by various evaluations of concrete, for example, M20, M50, and M60 and furthermore shifting rates of ternary mix and fibers. The test examinations explored the proposed specimens and find the compressive strength, split tensile strength, and flexural strength. The proposed ternary blended concrete with hybrid fibers upgraded the mechanical properties and optimal strength.
\end{abstract}

Keywords: Ternary Blended Fiber Reinforced Concrete, steel and polypropylene, fibers, MK, FA, GGBS.

Cite this Article: K. Nagaraja and H. Sudarshan Rao, An Experimental Investigation of Ternary Blended Hybrid Fiber Reinforced Concrete (MK: FA: GGBS): Steel \& Polypropylene Fibers. International Journal of Advanced Research in Engineering and Technology, 10(6), 2019, pp. 202-216.

http://iaeme.com/Home/issue/IJARET?Volume=10\&Issue $=6$

\section{INTRODUCTION}

In modern technology, concrete in construction industry develops their field by adding different materials and various proportions [1]. During the previous decades, we have seen numerous 
researchers' concrete by supplanting with numerous materials in an appropriate manner to decrease the economy and contamination. A few blends of binary blended concrete or ternary blended concrete could be increased because of possible assets in different nations [2-4]. These blends have institutionalized the world over, for example, pozzolanic cements, Portland slag cement, RHA cement and limestone filler Portland cements. To use materials all the more viably and lessen the expense in the development industry, ternary blend is made with Portland clinkers and additional 2 admixtures might be a superior alternative since it displays a few focal points concluded binary cements [5-7].

With the improvement of isolated pounding and blending innovation in cement industry, it is getting progressively helpful to create these supposed market-situated or customized cements [8-10]. Triple blended concretes have a place with those strata of concretes where the quality and solidness attributes are boosted to the most noteworthy degree conceivable, in contrast with different kinds of concretes, by the unobtrusive fitting of its synthetic creation, fineness and particle size dispersion [11-13]. The worries with the second-rate break sturdiness of concrete are relieved to an enormous degree by strengthening it with fibers of different materials. The subsequent material with an irregular circulation of short, spasmodic fibers is named fiber reinforced concrete (FRC) [14-17]. In this examination, work displays the novel idea for creating ternary blended concrete with including half and half fibers. The mechanical properties are examined for the proposed ternary blended concrete and approved utilizing simulation modeling.

\section{LITERATURE REVIEW}

Shon, C.- S et al. in 2018 [18] had researched that the different types of concrete like plain, ternary blended, and binary blended concrete makes with OPC, silica fume, and flyash. The basic air-void dividing factors for blended concretes are 60\% DF was resolved to be $198.2 \mu \mathrm{m}$ and $305.2 \mu \mathrm{m}$, individually. In addition, ternary blends brought about higher FRN than other two blends.

Lim, J. S et al. in 2019 [19] had inspected to set up the plausibility of utilizing EAFS as a total substitute of NGR as the coarse aggregate of concrete by means of additional modern waste materials in the cover and fine total stage. Furthermore, the techniques for optimization on the OPC-GGBS-PFA as a ternary blended cover framework were likewise settled. In the meantime, the ideal blend of compound admixture dose was additionally decided in this investigation.

M. Anwar, et al. in 2019 [20] had proposed e trial work aftereffects of tried examples of nine concrete blends. Blends arranged by water to cementitious mixes proportion of 0.4, - 0.6. These blends incorporate Portland cement, fly ash, and silica fume as ternary arrangement of cementitious mixes. The deliberate properties contain air substance, sprawl, and entity weight for the crisp state even as the deliberate property for the case-hardened concrete incorporate compressive and rigidities, static and dynamic young module's and pulsate speed.

In 2019, Nagaratnam, B et al. [21] had introduced that the achievability of using palm oil fuel ash (POFA) and FA as an OPC substitute in self-compacting concretes (SCC). The degree of OPC substitution is capable of $40 \%$ dependent on a $540 \mathrm{~kg} / \mathrm{m} 3$ blend plan. Compressive quality of SCC was resolved at 7, 28 and 90 days utilizing the two 3D squares and chambers. The connection with the parting rigidity was assessed. $\mathrm{Ca}(\mathrm{OH})_{2}$ evacuation was estimated by Differential Thermal Analysis and its microstructure properties identified utilizing the Scanning Electron Microscopy. When contrasting the POFA and FA, it was discovered that the FA beat POFA for equivalent OPC replacements. 
Jung, S. H et al. in 2017 [22] had examined the field achievability of a recently created ternary blended concrete mix \& impact on moderating thermal splitting in huge concrete structures. 4 false up test individuals were thrown utilizing various sorts of cementations fasteners, \& varieties in temperature and strain with time was observed for these individuals. These techniques indicated that decreased warmth of hydration in the ternary blend essentially lessened varieties in temperature and strain in the test part.

\section{EXPERIMENTAL INVESTIGATION OF TERNARY BLENDED CONCRETE}

The fundamental aim of the proposed research work is to enhance the investigation of ternary blended concrete with hybrid fibers. In this examination, the mix design of M20, M50, M60 and M70 is inspected under the ternary mix of GGBS, Fly debris, and Metakaolin as fractional substitution by weight of cement at different rates. Furthermore, to enhance the strength of the ternary blended concrete, hybrid fibers are included (steel and polypropylene). By utilizing these materials, we build efficiently and to decide compressive strength, split tensile strength, flexural strength of concrete blend of the considerable number of evaluations.

\subsection{Materials, Mixtures and Testing Procedure}

The mechanical behavior of proposed concrete arranged with high rates of ternary mixes like MK, FA, GGBS and hybrid fibers (steel and polypropylene) with different volume parts are examined. The examination manages the experimental study to find the properties of hybrid fiber reinforced concrete. The specimens are set up by various evaluations of concrete, for example, M20, M50, M60 and M70 and furthermore fluctuating rates of ternary mix and fibers. The sample preparation and test investigation are clarified detail as beneath:

\subsubsection{Materials Required}

Each experiment that are embraced to decide the qualities of materials are worked according to system given by applicable Indian principles. Ternary concrete blends incorporate three diverse cementitious materials. Mineral admixtures like MK $(0,5 \%, 10 \%, 15 \%, 20 \%, 25 \%$ and 30\%), GGBS $(0,5 \%, 10 \%, 15 \%, 20 \%, 25 \%$ and $30 \%)$ and Fly ash $(0,5 \%, 10 \%, 15 \%, 20 \%, 25 \%$ and $30 \%$ ) have been utilized alongside cement and triple blended bond concrete blends (table 1) are readied. An adequate number of cubes, cylinders, and prisms are cast and these specimens are tried for the adjustment in compression, strain and flexural strength at 28 days. The volume part of Hybrid Fibers (HF) fluctuated in the level of SF as $(0,0.5,1,1.5$, and $2 \%)$ and PF as $(0,0.1$, $0.2,0.3,0.4$, and $0.5 \%$ ). Here, the mechanical properties, for example, compressive strength, tensile strength, and flexural strength, are examined dependent on these three restoring days. The blending techniques were performed by the ENTREY SHOCK LACE strategy. The material utilized in this examination comprises of OPC-53 Grade, coarse aggregate (It goes through $10 \mathrm{~mm}$ IS strainer), manufactured sand, to upgrade the fresh properties of the blend are included ternary blended concrete.

Table 1 Materials and their quantities used in our experimental investigation

\begin{tabular}{|c|c|c|c|c|c|c|c|c|}
\hline Grade & Mix & $\begin{array}{c}\text { Cement } \\
(\mathbf{k g})\end{array}$ & Metakaolin (\%) & $\begin{array}{c}\text { Fly ash } \\
\mathbf{( \% )}\end{array}$ & $\begin{array}{c}\text { GGBS } \\
\mathbf{( \% )}\end{array}$ & $\begin{array}{c}\text { SF } \\
(\%)\end{array}$ & $\begin{array}{c}\text { PF } \\
(\%)\end{array}$ & $\begin{array}{c}\text { Aspect } \\
\text { ratio }\end{array}$ \\
\hline M20 & $1: 1.5: 3$ & $60-100$ & $0-30$ & $0-30$ & $0-30$ & $0-2$ & $0.1-0.5$ & 60 \\
\hline M50 & $\begin{array}{c}\text { Design } \\
\text { Mix }\end{array}$ & $60-100$ & $0-30$ & $0-30$ & $0-30$ & $0-2$ & $0.1-0.5$ & 60 \\
\hline M60 & $\begin{array}{c}\text { Design } \\
\text { Mix }\end{array}$ & $60-100$ & $0-30$ & $0-30$ & $0-30$ & $0-2$ & $0.1-0.5$ & 60 \\
\hline M70 & $\begin{array}{c}\text { Design } \\
\text { Mix }\end{array}$ & $60-100$ & $0-30$ & $0-30$ & $0-30$ & $0-2$ & $0.1-0.5$ & 60 \\
\hline
\end{tabular}


Cement-Locally accessible OPC 53 grade affirming ISI benchmarks has exist available and subsequent examination are completed.

\section{Aggregates}

Fine aggregate: In this present examination, locally accessible waterway sand was utilized as fine aggregate. The aggregates were washed $\&$ screened at site to evacuate malicious materials and tried according to seems to be: 383-1970.

Coarse Aggregate: The blue rock squashed stone aggregates of $20 \mathrm{~mm}$ most extreme size were utilized as coarse aggregates for the present examination. The aggregate was tried according to the strategy given in: 383-1970 and IS: 2386-1963.

Water: Water fitting in with the necessities of IS: 456-2000 is seen as reasonable for making concrete. It is commonly expressed that if the water is fit for drinking, it is additionally fit for making concrete. In this present examination, drinking water was utilized for making concrete and restoring.

\section{Admixtures}

Fly ash: Fly ash is a heterogeneous offshoot material created in the burning procedure of coal utilized in power stations. It is a superior dark hued powder having circular shiny particles that ascent with the pipe gases. The specific gravity of fly ash sorts from a short estimation of 1.90 for a sub-bituminous ash to a maximum estimation of 2.96 for an iron-rich bituminous debris.

Metakaolin: Metakaolin is a significant admixture for concrete or potentially bond applications. Kaolin is a excellent, white, mud mineral which has been customarily utilized in the construction of porcelain. Metakaolin when utilized as an incomplete substitution substance for bond in concrete. The pozzolanic reaction begins soon and proceeds between 7 to 28 days. The physical and chemical properties of metakaolin are appeared in table 2 and 3.

Table 2 Metakaolin: Physical properties

\begin{tabular}{|l|l|}
\hline Specific gravity & 2.4 to 2.6 \\
\hline Physical form & Powder \\
\hline Color & Off white, Gray to Buff \\
\hline BET & $15 \mathrm{~m} 2 /$ gram \\
\hline Specific surface & $8-15 \mathrm{~m} 2 / \mathrm{g}$ \\
\hline
\end{tabular}

Table 3 Metakaolin: Chemical properties

\begin{tabular}{|c|c|c|c|c|c|c|c|c|c|c|c|}
\hline $\begin{array}{c}\text { Chemical } \\
\text { names }\end{array}$ & $\mathrm{SiO}_{2}$ & $\mathrm{AlO}_{2}$ & $\begin{array}{c}\mathrm{Fe} 2 \mathrm{O} \\
3\end{array}$ & $\begin{array}{l}\mathrm{Ti} \\
\mathrm{O}_{2}\end{array}$ & $\mathrm{SO}_{4}$ & $\begin{array}{c}\mathrm{Li}_{2} \mathrm{O} \\
5\end{array}$ & $\mathrm{CaO}$ & $\mathrm{MgO}$ & $\mathrm{Na2O}$ & $\mathrm{K} 2 \mathrm{O}$ & L.O.I \\
\hline Values & $\begin{array}{c}51- \\
53 \%\end{array}$ & $\begin{array}{l}42- \\
44 \%\end{array}$ & $\begin{array}{c}<2.20 \\
\%\end{array}$ & $\begin{array}{l}<3 \\
\%\end{array}$ & $\begin{array}{c}<0.5 \\
\%\end{array}$ & $\begin{array}{c}<0.2 \\
\%\end{array}$ & $\begin{array}{c}<0.20 \\
\%\end{array}$ & $\begin{array}{c}<0.10 \\
\%\end{array}$ & $\begin{array}{c}<0.05 \\
\%\end{array}$ & $\begin{array}{c}<0.40 \\
\%\end{array}$ & $\begin{array}{c}<0.50 \\
\%\end{array}$ \\
\hline
\end{tabular}

GGBS: It is a blast furnaces utilized to create iron. GGBS carried out at a temperature of approximately $1500^{\circ}$ centigrade and are continued with a deliberately illicit mix of iron mineral, coke \& limestone.

\section{Fibers}

Steel Fiber (SF): SF are low carbon, cold drawn steel wire fibers intended to furnish concrete with temperature and shrinkage split control, upgraded flexural support, improved shear strength and increment the break opposition of concrete.

Polypropylene fiber (PF): PF are likewise utilized in showered concrete, to improve the underlying properties and to lessen sloughing and bounce back. Expansion of PP fibers in concrete expands the splitting tensile strength by approx $20 \%$ to half. 


\subsubsection{Testing Parameters and its Dimensions}

Compressive strength analysis was performed on standard solid cubes of $100 \times 100 \times 100 \mathrm{~mm}$. The specimens were accumulated in molds for $24 \mathrm{~h}$. After de-formed cubes are kept in ordinary water for curing, the compressive strength was tried after finish of separate restoring periods. Splitting tensile strength was directed on $150 \times 300 \mathrm{~mm}$ cylindrical shaped test specimen to assess the tensile capacity gave by concrete. FS test was led on prisms of measurements $100 \mathrm{~mm}$ x $100 \mathrm{~mm} \times 500 \mathrm{~mm}$ for restoring days utilizing flexural test machine and the outcomes were organized. The specimen details are appeared in table 4.

Table 4 Specimen details

\begin{tabular}{|c|c|c|c|}
\hline Specimens & Specimens name & Cement & Fibers \\
\hline S1 & M5F5G5 & \multirow{24}{*}{$\begin{array}{l}60,65,70,75,80,85,90 \\
95,100 \mathrm{~kg}\end{array}$} & 0 \\
\hline $\mathrm{S} 2$ & M10F10G10 & & 0 \\
\hline S3 & M15G15F15 & & 0 \\
\hline S4 & M20G20F20 & & 0 \\
\hline S5 & M25G25F25 & & 0 \\
\hline S6 & M30G30F30 & & 0 \\
\hline S7 & M5F5G5SF & & \multirow{6}{*}{$0.5 \%, 1 \%, 1.5 \%, 2 \%$} \\
\hline S8 & M10F10G10SF & & \\
\hline S9 & M15G15F15SF & & \\
\hline S10 & M20G20F20SF & & \\
\hline S11 & M25G25F25SF & & \\
\hline S12 & M30G30F30SF & & \\
\hline $\mathrm{S} 13$ & M5F5G5PF & & \multirow{6}{*}{$\begin{array}{c}0.1 \%, 0.2 \%, 0.3 \%, 0.4 \% \text {, } \\
0.5 \%\end{array}$} \\
\hline S14 & M10F10G10PF & & \\
\hline $\mathrm{S} 15$ & M15G15F15PF & & \\
\hline S16 & M20G20F20PF & & \\
\hline S17 & M25G25F25PF & & \\
\hline S18 & M30G30F30PF & & \\
\hline S19 & M5F5G5HF & & \multirow{6}{*}{$\begin{array}{c}\text { SF- } 0.5-2 \% \\
\text { HF- } 0.1-0.5 \%\end{array}$} \\
\hline $\mathrm{S} 20$ & M10F10G10HF & & \\
\hline $\mathrm{S} 21$ & M15G15F15HF & & \\
\hline $\mathrm{S} 22$ & M20G20F20HF & & \\
\hline S23 & M25G25F25HF & & \\
\hline S24 & M30G30F30HF & & \\
\hline
\end{tabular}

\subsubsection{Testing Procedure}

In the present examination triple blending cement concrete mixes have been examined for different strength properties. The individual rates of ternary blended concrete have been shifted from $0 \%$ to $30 \%$ as substitution of cement. Steel fibers of $1 \mathrm{~mm}$ dia and $50 \mathrm{~mm}$ length with a aspect ratio of 60 have been attempted alongside above mixes.

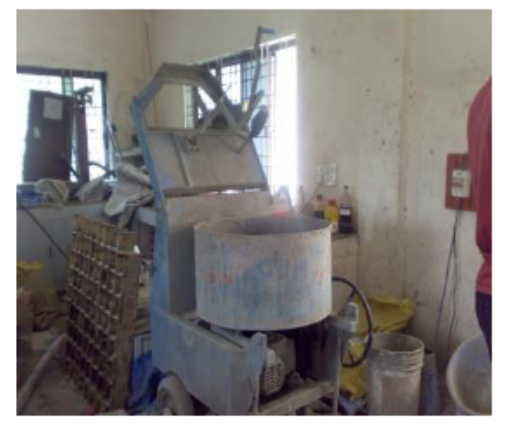

(a)

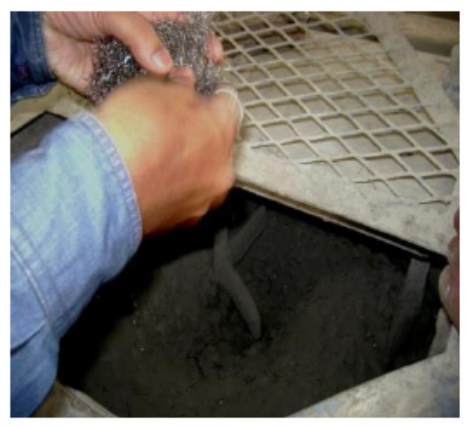

(b)

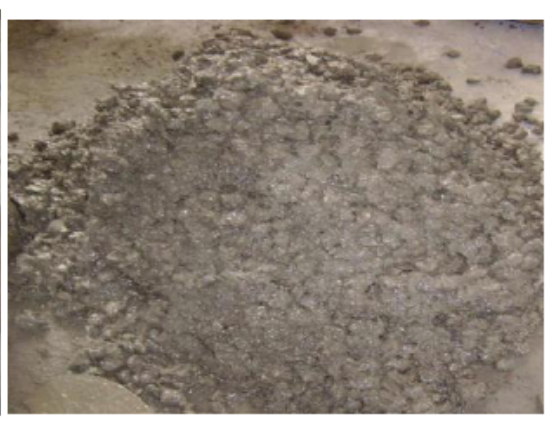

(c)

Figure 1 (a) PAN mixer (b) Fibers added in concrete mix (c) Fresh concrete Mix 


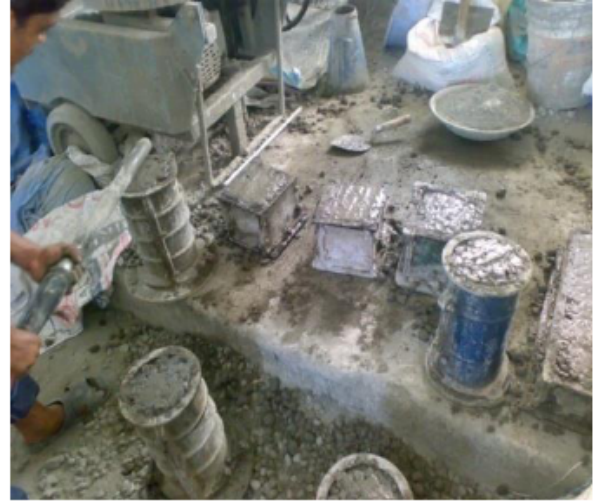

(a)

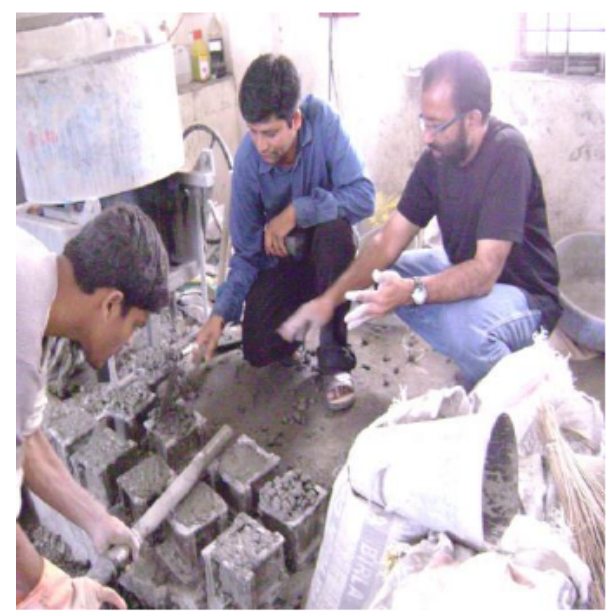

(c)

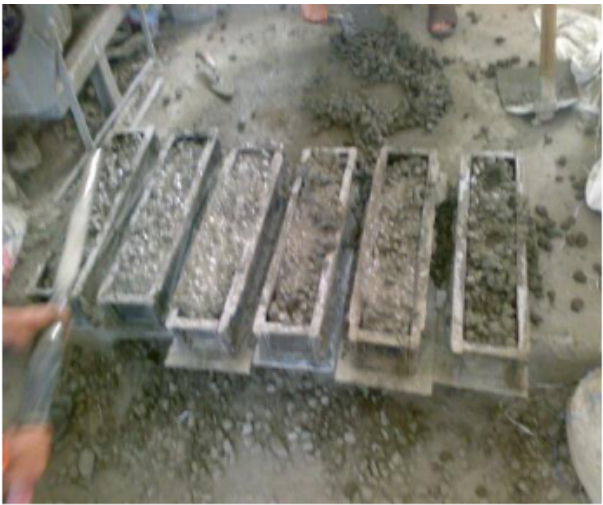

(b)

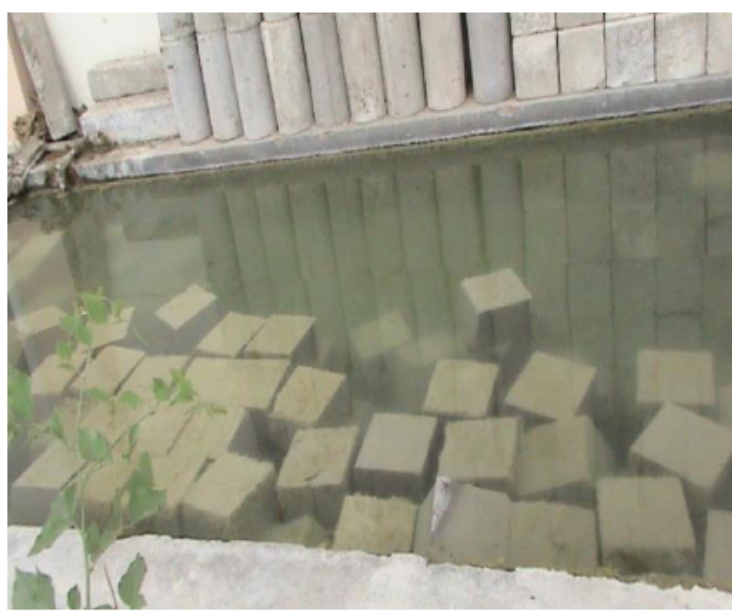

(d)

Figure 2 Specimen Preparation (a) Cylinder and cubes (b) Beams (d) Cube preparation (d) Curing specimens

The examples were cast and afterward demolded following 24 hours of throwing and kept in a water tanks for 7 and 28 days to fix. Agent tests of the materials of the concrete for use were gotten via cautious inspecting. Test tests of cement were comprised of a little segment taken from every one of various packs nearby. Test tests of aggregates were taken from bigger parcels by quartering and sieving. Completely blended concrete is filled in to form. Each layer of concrete in the shape was vibrated utilizing a vibrating table till the predefined condition was accomplished and till each corner and void inside the form was not totally and appropriately filled. In this examination we have set aside the relieving effort to be that of 28 days (figure 1 and 2).

\subsubsection{Casting and Curing}

The prepared samples are processed for casting and leaving them in a dry spot for 24 hours were accumulated at a position free from shaking, in moist air having in any event $90 \%$ comparative moistness and at a temperature of $27^{\circ} \mathrm{C}+2^{\circ} \mathrm{C}$ for 24 hours $+1 / 2$ hour starting the hour of development of water to the dry fixings. Following this time, the specimens were checked \& expelled from the molds and afterward quickly inundated in perfect, place water and kept there until taken out only before test. The water where the specimens were submerged were reestablished like clockwork and kept up at a temperature of $27^{\circ} \mathrm{C}+2^{\circ} \mathrm{C}$. The specimens were not allowable to get dry when they have been investigated. 


\subsection{Validating the structure using Artificial Neural Network (ANN)}

Following to analysis the model, performances are predicted by utilizing optimization algorithms in MATLAB work bench. The optimization techniques dissected the behavior of each samples and predicted the strength of samples by fluctuating loads. With the aim of amplifying the precision of accuracy, we go for the techniques like ANN. Neural Networks (NN) have solid basics encircled dependent on the biological neural network and perform calculations like the regular neural networks (figure 3).

Artificial neural networks utilize various layers of scientific processing to understand the data it's fed. ANN comprises of in any event 3 layers of neurons: (i) an input layer, (ii) hidden layer, and (iii) an output layer.

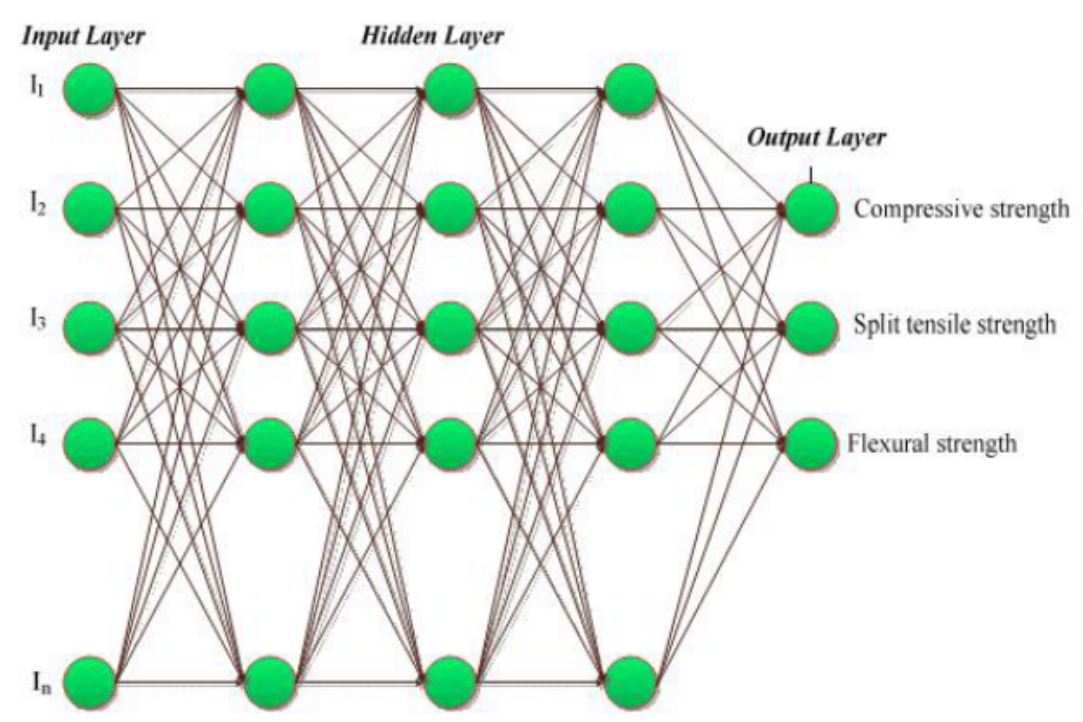

Figure 3 ANN architecture

\subsubsection{Steps of $A N N$}

- Initially, the input parameters, for example, mix proportions; cement ratio, fiber properties and aspect ratio are given to the input layer in ANN for every specimen.

- The hidden layer records various neurons which are portrayed as $H_{1}, H_{2}, \ldots \ldots \ldots . H_{n}$ the hidden layers are associated with the output layer by utilizing the neurons. The input layer weight $\alpha_{w j}$ and the hidden layer weights $\beta_{w i j}$ are instated in this layer. The fundamental, just as activation capacity of the ANN structure, is assessed by utilizing the condition (1).

$$
B_{b}=\sum_{j=1}^{N} I_{i} \times \beta_{w i j}
$$

Where $B_{b}$ symbolizes the basis function; $I_{i}$ indicates the input parameters $I_{i}=\left\{I_{1}, I_{2}, I_{3}, \ldots \ldots . . I_{n}\right\} ; A_{a}$ symbolizes the activation function, and $N$ refers to the number of data.

- Compute the fitness estimation of every arrangement and afterward compute the best arrangement esteems. Here, we accept the optimal fitness as low MSE rate. 
An Experimental Investigation of Ternary Blended Hybrid Fiber Reinforced Concrete (MK: FA: GGBS):

Steel \& Polypropylene Fibers

$$
R_{f}=\min \left(\frac{\sum_{i=1}^{D_{N}}\left(A_{v i}-P_{v i}\right)^{2}}{N_{D}}\right)
$$

Where $R_{f}$ refers the Fitness function, $A_{v i}$ indicates experimental value, $P_{v i}$ shows the predicted value, and $N_{D}$ signifies the number of data.

- The hidden layer neurons are related with the output layer by the neurons. Each affiliation has a weighted worth, for instance, $\alpha_{w 1}, \alpha_{w 2}, \ldots \ldots . \alpha_{w n}$. The basis function of the output units is imparted by the condition is $F_{\text {output }}$ and the output is compressive strength, split tensile strength and flexural strength of each specimen.

$$
R_{l_{-} \text {output }}=\sum_{i=1}^{n} \alpha_{w} \sigma_{w}\left\{R_{i_{-} \text {optimal }}\right\} \quad l=1, i \in 1
$$

In this layer, we obtain the optimal output of ternary blended concrete for all the specimens. The validation of this simulation modeling reduces the MSE rate compared with experimental modeling.

\section{EXPERIMENTAL RESULTS}

The results of proposed exploratory and simulation study are analyzed in this part. In the assessment of Ternary blended concrete, the proposed technique utilized the parameters, for example, compressive strength, Flexural strength, split tensile strength for which are processing the presentation of the proposed structure. From that point onward, the exploratory investigation is approved utilizing a soft computing method that is actualized in the operational foundation of MATLAB programming adaptation 2016a with 4GB RAM and i5 processor. The predicted results are compared with trial and current methodologies with the assistance of diagrams, graphs, and tables.

Effects of compressive strength: This strength of triple blended concrete was discovered depends on IS 1905: 1987. The compressive strength is meant as

$$
\sigma_{c}=\left[\frac{L_{U}}{A}\right]
$$

The basic compressive strength is denoted as

$$
\sigma_{b}=0.25 \times F_{c s}
$$

Where $L_{U}$ speaks to an ultimate load; $A$ demonstrate the area of specimen. The compressive testing machine, which has been utilized in our task, is of a solid kind and of sufficient boundary with respect to the analysis. Its admissible permissible isn't more noteworthy than +2 percent of the greatest load. The testing machine is providing with two steel bearing platens with solidified expressions. The additional weight platen is a plain inflexible bearing block. Figure 4 shows the compressive strength investigation analysis utilized in our experimentation. 


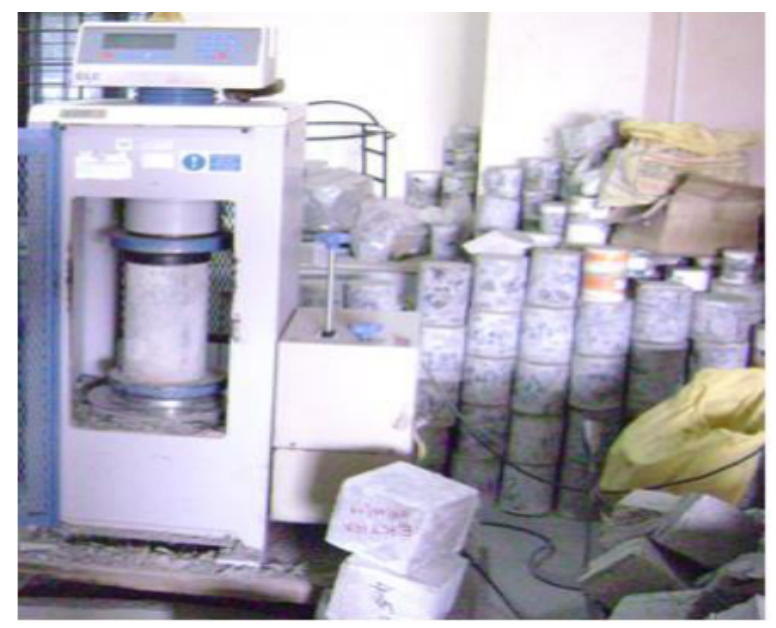

Figure 4 Compressive strength testing setup in our investigation

The bearing faces of both the platens bigger than the ostensible size of the specimen to which the load is applied. The bearing surfaces of the platens don't leave from a plane by more than $0.01 \mathrm{~mm}$ anytime and they are kept up with a reasonable variety point of confinement of $0.02 \mathrm{~mm}$. The versatile bit of the circularly situated pressure platen is hung on the round seat however the structure is with the end goal that the bearing face is pivoted unreservedly and can be tilted through little points toward any path. The tests are made at the perceived times of the test specimens, the most common being 28 days. The dried specimen was set on the testing machine. The load was functional devoid of stun \& expanded ceaselessly at a pace of around $140 \mathrm{~kg} / \mathrm{sq} . \mathrm{cm} / \mathrm{min}$ until the opposition of the specimen to the expanding load separated and no extra famous load could be supported. The highest load is applied to the specimen was then recorded and the presence of the concrete was noted (table 5, 6 and 7).

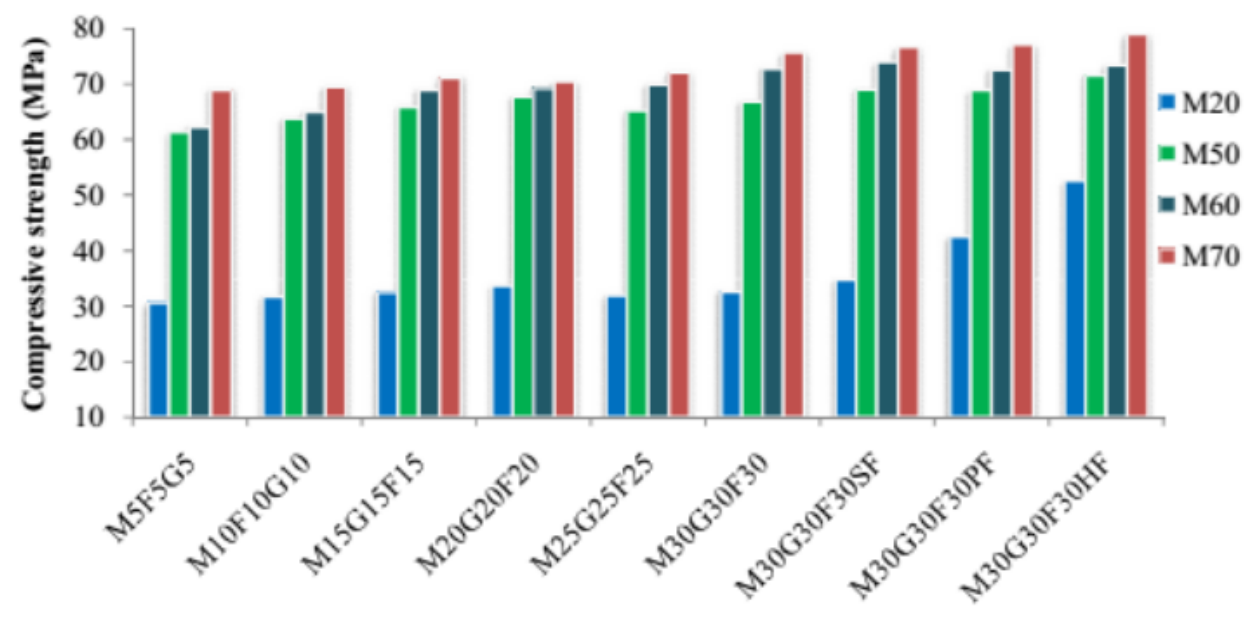

Figure 5 Compressive strength analysis

Figure 5 depicts the result of CS by varying four grades M20, M50, M60 and M70. For the examination of ternary blended concrete we are taking the MK, GGBS, and FA by differ the level of $0-30 \%$. By expanding the level of blended blends the concrete invigorates high strength as improving the strength by including the fibers. In the correlation of including hybrid fibers with the level of $0.5-2 \%$ and $0.1-0.5 \%$, the fibers with most extreme range achieves the greatest compressive strength as $445 \mathrm{MPa}$ in $\mathrm{M} 20$ grade, $67 \mathrm{MPa}$ in M50grade $70 \mathrm{MPa}$ in M70 grade and $67 \mathrm{MPa}$ in M60 grade. 
An Experimental Investigation of Ternary Blended Hybrid Fiber Reinforced Concrete (MK: FA: GGBS): Steel \& Polypropylene Fibers

Table 5 Results of proposed investigation (M20 grade)

\begin{tabular}{|c|l|c|c|c|c|c|c|}
\hline $\begin{array}{c}\text { Concrete } \\
\text { grades }\end{array}$ & Mix design & $\begin{array}{c}\text { CS MPa } \\
\text { (Experimental) }\end{array}$ & $\begin{array}{c}\text { Predicted } \\
\text { CS (MPa) }\end{array}$ & $\begin{array}{c}\text { STS } \\
\text { (MPa) } \\
\text { (Exp) }\end{array}$ & $\begin{array}{c}\text { Predicted } \\
\text { STS } \\
\text { (MPa) }\end{array}$ & $\begin{array}{c}\text { FS } \\
\text { (MPa) } \\
\text { (Exp) }\end{array}$ & $\begin{array}{c}\text { Predicted } \\
\text { FS } \\
\text { (MPa) }\end{array}$ \\
\hline \multirow{6}{*}{} & M5F5G5 & 30.6 & 30.6 & 2.84 & 2.84 & 7.81 & 7.9 \\
\cline { 2 - 8 } & M10F10G10 & 31.66 & 31.61 & 3.32 & 3.26 & 8.4 & 8.2 \\
\cline { 2 - 8 } & M15G15F15 & 32.48 & 32.53 & 3.76 & 3.74 & 9.11 & 9.12 \\
\cline { 2 - 8 } & M20G20F20 & 33.66 & 33.45 & 4.38 & 4.25 & 9.3 & 9.24 \\
\cline { 2 - 8 } & M25G25F25 & 31.92 & 31.92 & 3.5 & 3.36 & 9.6 & 9.67 \\
\cline { 2 - 8 } & M30G30F30 & 32.61 & 33.1 & 4.25 & 4.09 & 9.11 & 9.12 \\
\cline { 2 - 8 } & M5F5G5SF & 34.1 & 34.37 & 4.63 & 4.72 & 9.55 & 9.6 \\
\cline { 2 - 8 } & M10F10G10SF & 32.86 & 32.86 & 3.08 & 3.08 & 10 & 10.23 \\
\cline { 2 - 8 } & M15G15F15SF & 34.12 & 33.74 & 3.42 & 3.58 & 11.07 & 11.09 \\
\cline { 2 - 8 } & M20G20F20SF & 35.02 & 34.63 & 4.06 & 4.07 & 8.55 & 8.44 \\
\cline { 2 - 8 } & M25G25F25SF & 35.86 & 35.52 & 4.68 & 4.56 & 9.62 & 9.51 \\
\cline { 2 - 8 } & M30G30F30SF & 34.78 & 34.04 & 3.82 & 3.74 & 10.1 & 10.25 \\
\cline { 2 - 8 } & M5F5G5PF & 35.54 & 35.13 & 4.38 & 4.4 & 10.5 & 10.47 \\
\cline { 2 - 8 } & M10F10G10PF & 36.58 & 36.21 & 4.96 & 5.06 & 11.2 & 11.36 \\
\cline { 2 - 8 } & M15G15F15PF & 40.02 & 41.25 & 4.32 & 4.4 & 10.7 & 10.89 \\
\cline { 2 - 8 } & M20G20F20PF & 41.17 & 42.36 & 5.28 & 5.3 & 11.03 & 11.36 \\
\cline { 2 - 8 } & M25G25F25PF & 42.26 & 43 & 6.02 & 6.12 & 11.09 & 11.41 \\
\cline { 2 - 8 } & M30G30F30PF & 42.56 & 43.65 & 6.72 & 6.9 & 12.06 & 12.36 \\
\cline { 2 - 8 } & M5F5GHF & 41.75 & 42.15 & 5.5 & 5.9 & 12.45 & 12.41 \\
\cline { 2 - 8 } & M10F10G10HF & 43.05 & 44 & 6.53 & 6.6 & 12.49 & 12.4 \\
\cline { 2 - 8 } & M15G15F15HF & 43.52 & 43.05 & 7.22 & 7.3 & 12.95 & 12.96 \\
\cline { 2 - 8 } & M20G20F20HF & 49.24 & 51.9 & 7.35 & 7.21 & 13.36 & 13.12 \\
\cline { 2 - 8 } & M25G25F25HF & 50.98 & 53.82 & 7.65 & 7.7 & 13.48 & 13.33 \\
\cline { 2 - 8 } & M30G30F30HF & 52.58 & 54.53 & 7.7 & 7.71 & 13.56 & 13.6 \\
\hline
\end{tabular}

Table 6 Results of proposed investigation (M50 grade)

\begin{tabular}{|c|l|c|c|c|c|c|c|}
\hline $\begin{array}{c}\text { Concrete } \\
\text { grades }\end{array}$ & Mix design & $\begin{array}{c}\text { CS MPa } \\
\text { (Experimental) }\end{array}$ & $\begin{array}{c}\text { Predicted } \\
\text { CS (MPa) }\end{array}$ & $\begin{array}{c}\text { STS } \\
\text { (MPa) } \\
\text { (Exp) }\end{array}$ & $\begin{array}{c}\text { Predicted } \\
\text { STS } \\
\text { (MPa) }\end{array}$ & $\begin{array}{c}\text { FS } \\
\text { (MPa) } \\
\text { (Exp) }\end{array}$ & $\begin{array}{c}\text { Predicted } \\
\text { FS (MPa) }\end{array}$ \\
\hline \multirow{6}{*}{} & M5F5G5 & 41.4 & 41.32 & 2.84 & 2.8 & 8.2 & 8.23 \\
\cline { 2 - 8 } & M10F10G10 & 43.81 & 43.51 & 3.29 & 3.55 & 9.12 & 9.16 \\
\cline { 2 - 8 } & M15G15F15 & 45.86 & 45.9 & 3.74 & 4.04 & 9.24 & 9.14 \\
\cline { 2 - 8 } & M20G20F20 & 47.72 & 47 & 4.25 & 4.51 & 9.67 & 9.68 \\
\cline { 2 - 8 } & M25G25F25 & 45.18 & 46.31 & 3.36 & 3.72 & 9.72 & 9.75 \\
\cline { 2 - 8 } & M30G30F30 & 46.86 & 47.77 & 4.09 & 4.35 & 9.79 & 9.78 \\
\cline { 2 - 8 } & M5F5G5SF & 44.15 & 45.12 & 2.99 & 2.9 & 8.5 & 8.43 \\
\cline { 2 - 8 } & M10F10G10SF & 47.36 & 47.05 & 3.08 & 3.11 & 8.9 & 8.91 \\
\cline { 2 - 8 } & M15G15F15SF & 44.25 & 44.52 & 3.42 & 3.4 & 9.14 & 9.16 \\
\cline { 2 - 8 } & M20G20F20SF & 45.36 & 45.99 & 4.06 & 4.12 & 9.24 & 9.26 \\
\cline { 2 - 8 } & M25G25F25SF & 45.32 & 45.15 & 4.5 & 4.47 & 9.5 & 9.54 \\
\cline { 2 - 8 } & M30G30F30SF & 49.36 & 49.11 & 4.53 & 4.58 & 10.23 & 10.2 \\
\cline { 2 - 8 } & M5F5G5FF & 46.31 & 46.62 & 3.82 & 3.94 & 8.26 & 8.3 \\
\cline { 2 - 8 } & M10F10G10PF & 46.95 & 46.85 & 4.38 & 4.41 & 8.69 & 8.673 \\
\cline { 2 - 8 } & M15G15F15PF & 50.02 & 51 & 4.96 & 4.99 & 9.35 & 9.34 \\
\cline { 2 - 8 } & M20G20F20PF & 51.05 & 52.21 & 4.99 & 5.12 & 9.47 & 9.51 \\
\cline { 2 - 8 } & M25G25F25PF & 52.2 & 52.36 & 5.1 & 5.06 & 10.48 & 10.44 \\
\cline { 2 - 8 } & M30G30F30PF & 52.33 & 52.98 & 5.16 & 5.19 & 11.09 & 11.06 \\
\cline { 2 - 8 } & M5F5GHF & 50.36 & 51.47 & 4.32 & 4.33 & 8.96 & 8.99 \\
\cline { 2 - 8 } & M10F10G10HF & 51.47 & 50.06 & 5.28 & 5.14 & 9.65 & 9.78 \\
\cline { 2 - 8 } & M15G15F15HF & 52.36 & 52.85 & 6.02 & 6.09 & 10.69 & 10.78 \\
\cline { 2 - 8 } & M20G20F20HF & 53.33 & 53.34 & 6.72 & 6.78 & 10.87 & 10.92 \\
\cline { 2 - 8 } & M25G25F25HF & 53.69 & 54.33 & 5.5 & 5.56 & 11.06 & 11.32 \\
\cline { 2 - 8 } & M30G30F30HF & 54.14 & 54.96 & 6.53 & 6.58 & 11.54 & 11.64 \\
\hline
\end{tabular}


K. Nagaraja and H. Sudarshan Rao

Table 7 Results of proposed investigation (M60-grade)

\begin{tabular}{|c|l|c|c|c|c|c|c|}
\hline $\begin{array}{c}\text { Concrete } \\
\text { grades }\end{array}$ & Mix design & $\begin{array}{c}\text { CS MPa } \\
\text { (Experimental) }\end{array}$ & $\begin{array}{c}\text { Predicted } \\
\text { CS (MPa) }\end{array}$ & $\begin{array}{c}\text { STS } \\
\text { (MPa) } \\
\text { (Exp) }\end{array}$ & $\begin{array}{c}\text { Predicted } \\
\text { STS } \\
\text { (MPa) }\end{array}$ & $\begin{array}{c}\text { FS } \\
\text { (MPa) } \\
\text { (Exp) }\end{array}$ & $\begin{array}{c}\text { Predicted } \\
\text { FS (MPa) }\end{array}$ \\
\hline \multirow{6}{*}{} & M5F5G5 & 62.3 & 62.15 & 5.2 & 5.23 & 8.55 & 8.56 \\
\cline { 2 - 8 } & M10F10G10 & 65 & 65.32 & 5.5 & 5.26 & 9.62 & 9.71 \\
\cline { 2 - 8 } & M15G15F15 & 69 & 69.08 & 5.9 & 5.84 & 10.1 & 10.47 \\
\cline { 2 - 8 } & M20G20F20 & 69.32 & 69.41 & 6.1 & 6.15 & 10.5 & 10.4 \\
\cline { 2 - 8 } & M25G25F25 & 69.9 & 70.06 & 6.4 & 6.42 & 11.2 & 11.1 \\
\cline { 2 - 8 } & M30G30F30 & 72.8 & 72.9 & 6.98 & 6.9 & 11.7 & 11.5 \\
\cline { 2 - 8 } & M5F5G5SF & 63.3 & 64.07 & 5.29 & 5.3 & 8.56 & 8.5 \\
\cline { 2 - 8 } & M10F10G10SF & 65.6 & 65.78 & 5.51 & 5.55 & 8.98 & 8.9 \\
\cline { 2 - 8 } & M15G15F15SF & 69.33 & 70.88 & 5.96 & 5.9 & 9.56 & 9.53 \\
\cline { 2 - 8 } & M20G20F20SF & 69.98 & 71.47 & 6.21 & 6.3 & 10.35 & 10.5 \\
\cline { 2 - 8 } & M25G25F25SF & 70.14 & 70.07 & 6.47 & 6.44 & 10.59 & 10.6 \\
\cline { 2 - 8 } & M30G30F30SF & 71.56 & 72.44 & 7.14 & 7.21 & 11.13 & 11.16 \\
\cline { 2 - 8 } & M5F5G5PF & 64.05 & 65.54 & 5.33 & 6.48 & 8.7 & 8.45 \\
\cline { 2 - 8 } & M10F10G10PF & 64.47 & 65.31 & 5.58 & 5.61 & 8.8 & 8.9 \\
\cline { 2 - 8 } & M15G15F15PF & 65.36 & 66.04 & 6.14 & 6.21 & 9.46 & 9.56 \\
\cline { 2 - 8 } & M20G20F20PF & 67.89 & 67.35 & 6.39 & 6.37 & 10.42 & 10.36 \\
\cline { 2 - 8 } & M25G25F25PF & 69.84 & 69.55 & 7.08 & 7.14 & 10.52 & 10.96 \\
\cline { 2 - 8 } & M30G30F30PF & 72.58 & 73 & 7.14 & 7.36 & 11.29 & 11.36 \\
\cline { 2 - 8 } & M5F5G5HF & 65.36 & 64.78 & 5.41 & 5.46 & 8.79 & 8.61 \\
\cline { 2 - 8 } & M10F10G10HF & 68.33 & 68.14 & 5.7 & 5.72 & 8.82 & 8.8 \\
\cline { 2 - 8 } & M15G15F15HF & 68.84 & 68.99 & 6.46 & 6.5 & 9.51 & 9.6 \\
\cline { 2 - 8 } & M20G20F20HF & 70.47 & 71 & 6.94 & 6.97 & 10.48 & 10.47 \\
\cline { 2 - 8 } & M25G25F25HF & 71.69 & 71.19 & 7.45 & 7.4 & 10.69 & 10.7 \\
\cline { 2 - 8 } & M30G30F30HF & 73.42 & 73 & 7.51 & 7.55 & 12.06 & 12.45 \\
\hline
\end{tabular}

Table 8 Results of proposed investigation (M70- grade)

\begin{tabular}{|c|c|c|c|c|c|c|c|}
\hline $\begin{array}{l}\text { Concrete } \\
\text { grades }\end{array}$ & Mix design & $\begin{array}{l}\text { CS MPa } \\
\text { (Experimental) }\end{array}$ & $\begin{array}{l}\text { Predicted } \\
\text { CS (MPa) }\end{array}$ & $\begin{array}{l}\text { STS } \\
\text { (MPa) } \\
\text { (Exp) }\end{array}$ & $\begin{array}{l}\text { Predicted } \\
\text { STS } \\
(\mathrm{MPa})\end{array}$ & $\begin{array}{l}\text { FS (MPa) } \\
\text { (Exp) }\end{array}$ & $\begin{array}{l}\text { Predicted } \\
\text { FS } \\
(\mathrm{MPa})\end{array}$ \\
\hline \multirow{24}{*}{ M70 } & M5F5G5 & 69 & 69.32 & 5.5 & 5.56 & 10.36 & 10.45 \\
\hline & M10F10G10 & 69.54 & 70.01 & 5.9 & 5.84 & 10.89 & 10.98 \\
\hline & M15G15F15 & 71.12 & 71.14 & 5.98 & 6.12 & 11.36 & 11.4 \\
\hline & M20G20F20 & 70.45 & 71 & 6.2 & 6.21 & 11.41 & 11.5 \\
\hline & M25G25F25 & 72.15 & 70.89 & 6.64 & 6.7 & 12.36 & 12.1 \\
\hline & M30G30F30 & 75.68 & 75.33 & 7.12 & 7.15 & 12.41 & 12.6 \\
\hline & M5F5G5SF & 69.5 & 69 & 5.54 & 5.5 & 10.39 & 10.5 \\
\hline & M10F10G10SF & 70.15 & 71 & 5.96 & 5.99 & 10.9 & 10.98 \\
\hline & M15G15F15SF & 72.36 & 73.45 & 6.12 & 6.05 & 11.5 & 11.6 \\
\hline & M20G20F20SF & 71.66 & 72.03 & 6.25 & 6.29 & 11.98 & 12.06 \\
\hline & M25G25F25SF & 73.98 & 74 & 6.74 & 6.89 & 12.45 & 12.54 \\
\hline & M30G30F30SF & 74.69 & 74.15 & 6.9 & 6.84 & 12.69 & 12.9 \\
\hline & M5F5G5PF & 70.14 & 71.26 & 5.69 & 5.7 & 10.6 & 10.61 \\
\hline & M10F10G10PF & 70.14 & 72.6 & 6.17 & 6.14 & 10.87 & 10.9 \\
\hline & M15G15F15PF & 71.41 & 72.98 & 6.39 & 6.4 & 11.58 & 11.69 \\
\hline & M20G20F20PF & 73.22 & 74.74 & 6.9 & 6.91 & 11.78 & 11.85 \\
\hline & M25G25F25PF & 74.05 & 75 & 6.94 & 6.99 & 11.99 & 12.09 \\
\hline & M30G30F30PF & 74.14 & 76.32 & 7.36 & 7.4 & 12.96 & 13.05 \\
\hline & M5F5G5HF & 71.48 & 72.74 & 5.98 & 6.12 & 10.85 & 10.9 \\
\hline & M10F10G10HF & 72.58 & 73 & 6.34 & 6.4 & 11.23 & 11.36 \\
\hline & M15G15F15HF & 73.08 & 74.08 & 6.47 & 6.54 & 11.68 & 11.7 \\
\hline & $\mathrm{M} 20 \mathrm{G} 20 \mathrm{~F} 20 \mathrm{HF}$ & 74.89 & 75 & 7.15 & 7.2 & 11.97 & 12.08 \\
\hline & M25G25F25HF & 75.32 & 75.04 & 7.68 & 7.7 & 12.54 & 12.9 \\
\hline & M30G30F30HF & 79 & 78.36 & 7.9 & 7.5 & 13.12 & 13.15 \\
\hline
\end{tabular}


Effects of Split Tensile strength: As the biggest nominal size of aggregate doesn't surpass 20 $\mathrm{mm} / \mathrm{s}$ the size of test specimen made is $150 \mathrm{~mm}$ distance across x $300 \mathrm{~mm}$ height cylinders as proposed by IS Code. The load was applied with no shock and expanded always at an ostensible rate until the specimen falls flat (figure 5).

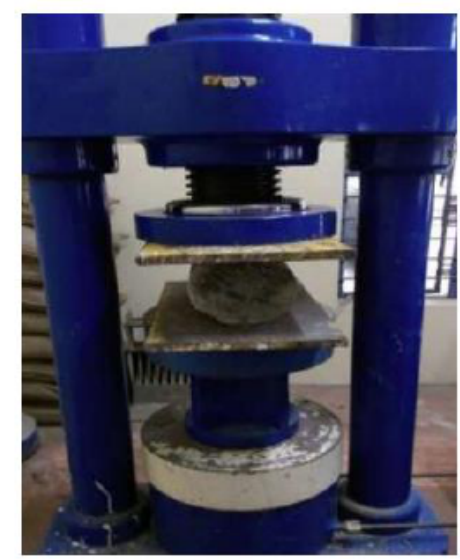

Figure 6 Split Tensile strength setup used in our investigation

The TS will influence the cracking performance, solidness, damping activity, sturdiness of concrete; in light of the split strength the behavior of concrete under shear loads are resolved. The tensile strength is resolved either by direct tensile tests or by indirect tensile tests, for example, split cylinder tests. In split tensile test cylinders following 28 days were expelled from the relieving tank and was left to dry for 24 hours following that sample is set for testing. Figure 7 shows the split tensile strength investigation for the proposed assessment. The evaluation of the concrete expanded the split tensile strength likewise expanded. On the off chance that the specimen is including the hybrid fibers with the scope of $2 \% \mathrm{SF}$ and the $0.5 \% \mathrm{PF}$, the STS run expanded up to $8.5 \mathrm{MPa}$ in M70 grade concrete.

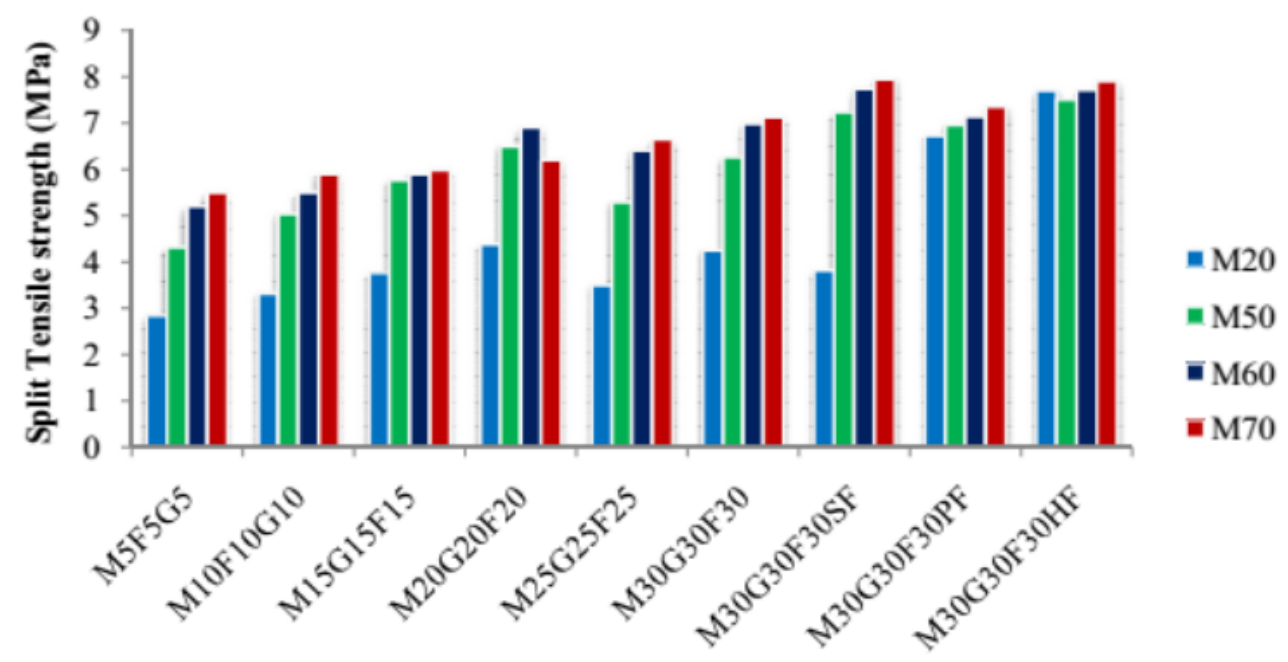

Figure 7 Split Tensile strength analysis

Effects of Flexural strength: The FS is the stress on the external surface of the specimen at failure, which ought to be joined by fiber break, as opposed to entomb laminar shear. Flexural strength of triple blended concrete by, 


$$
F_{s}=\left[\frac{3 U_{l}\left(l_{2}-l_{1}\right)}{2 H_{w p} W_{w p}}\right]
$$

Where $U_{l}$ speaks to an ultimate load; $l_{2}$ show the separation between two supports and $l_{1}$ implies the separation between two loading point. $H_{w p}$ Shows the height of the prism and $W_{w p}$ speaks to the width of the prism. Flexural strength recognizes the proportion of pressure and power an unreinforced strong piece, shaft or other structure can withstand to such a degree, that it contradicts any twisting frustrations.

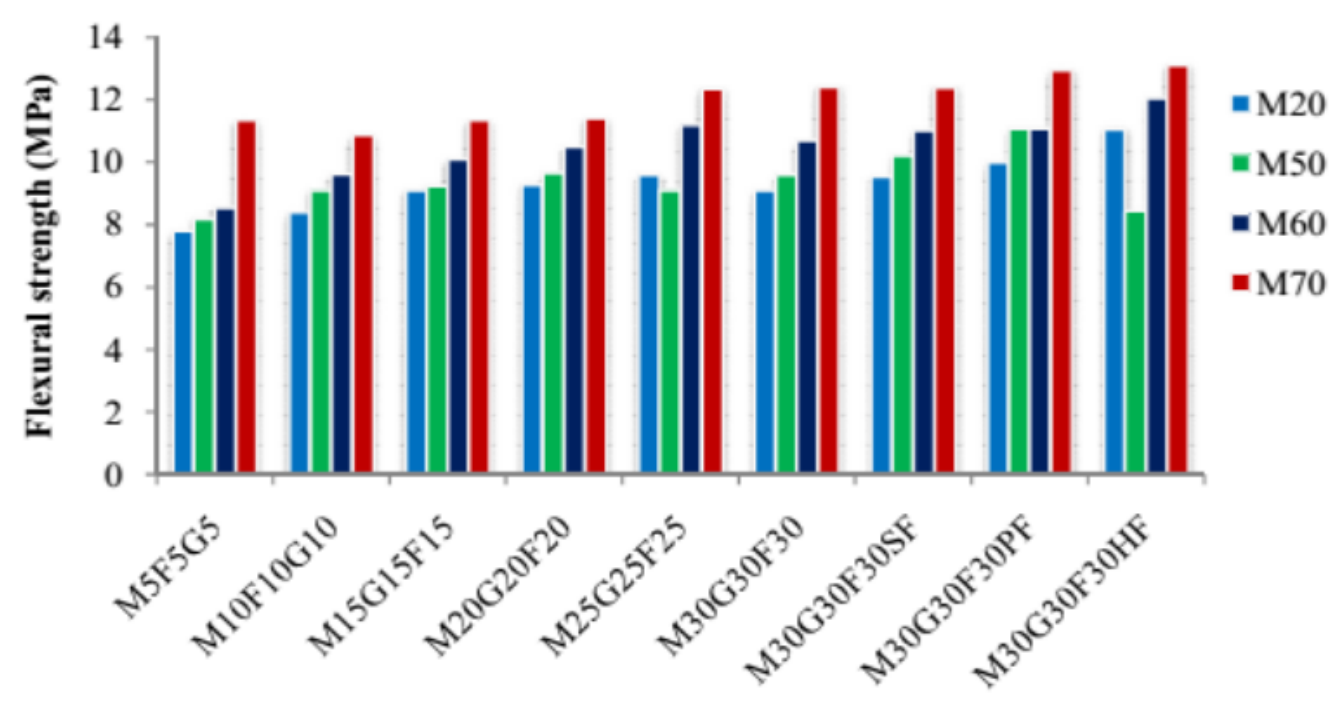

Figure 8 Flexural strength Analysis

Figure 8 shows the flexural strength analysis for M20, M50, M60 and M70 grade concrete. In this experimental analysis, the optimal flexural strength receives in the ternary blended concrete with hybrid fiber mixture grades. The output for M20 grade concrete only shown in the above presented table and the visualized result is presented in figure 8 . In table, the experimental result is compared with predicted result which is implemented in MATLAB software. The result predicted that the \% variation of actual and the predicted result are minimum in ANN method.

\section{CONCLUSION}

In the novel examination analyzed the mix of various fiber extents of steel and polypropylene within the sight of fly ash, GGBS and Metakaolin. The test results are finished up as pursues: It has been seen with the expansion of fibers in concrete, the strength of concrete at 28 days has expanded with different extents of the blend. The expansion of mechanical properties fluctuated in the scope of 30.6 to $79 \mathrm{Mpa}$ in compressive strength and 2.84 to 7.9 in split tensile strength and furthermore 7.8 to $13.81 \mathrm{MPa}$ in flexural strength. The mix of blended admixtures of 10 to $30 \%$ GGBS and $10-30 \% \mathrm{MK}$ and $10-30 \% \mathrm{FA}$ by fractional substitution by weight of concrete has indicated high increment in strength of specimen. Among the fibers rates, $2 \%$ is found to invigorate the most elevated compressive among all the sinewy blends. Contrast with a similar blend without fibers the strength increment is almost $15 \%$ and contrast with base blend it is $30.2 \%$. This triple blended blend in with hybrid fibers isn't just financially savvy additionally it renders the concrete to accomplish a few helpful properties. Based on the present exploratory investigation it is at last reasoned that ideal concrete blends can be gotten via doing significantly increase mixing with hybrid fibers. These blends groups higher strength as well as numerous other advantageous properties like better sturdiness, better break opposition, low penetrability, 
An Experimental Investigation of Ternary Blended Hybrid Fiber Reinforced Concrete (MK: FA: GGBS):

Steel \& Polypropylene Fibers

cost viability and so forth. Triple blended concrete blends are very appropriate for High Performance Concrete (HPC). Further work might be preceded with triple blended concrete blends utilizing other sort of mineral admixtures.

\section{REFERENCES}

[1] AzariJafari, H., Taheri Amiri, M. J., Ashrafian, A., Rasekh, H., Barforooshi, M. J., \& Berenjian, J. (2019). Ternary blended cement: an eco-friendly alternative to improve resistivity of high-performance self-consolidating concrete against elevated temperature. Journal of Cleaner Production.

[2] Arora, S., \& Singh, S. P. (2019). Probability of failure of RCA concrete with ternary blended cements. Construction and Building Materials, 225, 401-414.

[3] Vijaya Bhaskar Reddy, S., \& Srinivasa Rao, D. P. (2016). Experimental studies on compressive strength of ternary blended concretes at different levels of micro silica and ggbs. Materials Today: Proceedings, 3(10), 3752-3760.

[4] Sua-iam, G., Sokrai, P., \& Makul, N. (2016). Novel ternary blends of Type 1 Portland cement, residual rice husk ash, and limestone powder to improve the properties of selfcompacting concrete. Construction and Building Materials, 125, 1028-1034.

[5] Narender Reddy, A., \& Meena, T. (2018). A Study on Compressive Behavior of Ternary Blended Concrete Incorporating Alccofine. Materials Today: Proceedings, 5(5), 1135611363.

[6] Farahani, J. N., Shafigh, P., Alsubari, B., Shahnazar, S., \& Mahmud, H. B. (2017). Engineering properties of lightweight aggregate concrete containing binary and ternary blended cement. Journal of Cleaner Production, 149, 976-988.

[7] Bentz, D. P., Jones, S. Z., \& Snyder, K. A. (2015). Design and performance of ternary blend high-volume fly ash concretes of moderate slump. Construction and Building Materials, 84, 409-415.

[8] Sharfuddin Ahmed, M., Kayali, O., \& Anderson, W. (2008). Chloride penetration in binary and ternary blended cement concretes as measured by two different rapid methods. Cement and Concrete Composites, 30(7), 576-582.

[9] Erdem, T. K., \& Kirca, Ö. (2008). Use of binary and ternary blends in high strength concrete. Construction and Building Materials, 22(7), 1477-1483.

[10] Gesoğlu, M., Güneyisi, E., \& Özbay, E. (2009). Properties of self-compacting concretes made with binary, ternary, and quaternary cementitious blends of fly ash, blast furnace slag, and silica fume. Construction and Building Materials, 23(5), 1847-1854.

[11] Moser, R. D., Jayapalan, A. R., Garas, V. Y., \& Kurtis, K. E. (2010). Assessment of binary and ternary blends of metakaolin and Class $\mathrm{C}$ fly ash for alkali-silica reaction mitigation in concrete. Cement and Concrete Research, 40(12), 1664-1672.

[12] Cordeiro, G. C., Toledo Filho, R. D., Tavares, L. M., \& Fairbairn, E. M. R. (2012). Experimental characterization of binary and ternary blended-cement concretes containing ultrafine residual rice husk and sugar cane bagasse ashes. Construction and Building Materials, 29, 641-646.

[13] Shaikh, F.U.A., 2017. Mechanical properties of recycled aggregate concrete containing ternary blended cementitious materials. International Journal of Sustainable Built Environment, 6(2), pp.536-543.

[14] Owaid, H. M., Hamid, R., \& Taha, M. R. (2019). Durability properties of multiple-blended binder concretes incorporating thermally activated alum sludge ash. Construction and Building Materials, 200, 591-603.

[15] Wang, X.-Y. (2018). Analysis of hydration and strength optimization of cement-fly ashlimestone ternary blended concrete. Construction and Building Materials, 166, 130-140. 
[16] Vaičiukynienè, D., Pundienè, I., Kantautas, A., Augonis, A., Janavičius, E., Vaičiukynas, V., \& Alobeid, J. (2019). The synergic influence of dry sludge from waste water concrete plants and zeolitic by-product on ternary blended ordinary Portland cements properties. Journal of Cleaner Production, 118493.

[17] Reddy, M.V.S., Ashalatha, K. and Sasi, K., Strength Properties of Ternary Blended Concrete by Alccofine Bottom Ash Replacement in Cement and Blast Furnace Slag in Fine Aggregate.

[18] Shon, C.-S., Abdigaliyev, A., Bagitova, S., Chung, C.-W., \& Kim, D. (2018). Determination of air-void system and modified frost resistance number for freeze-thaw resistance evaluation of ternary blended concrete made of ordinary Portland cement/silica fume/class F fly ash. Cold Regions Science and Technology, 155, 127-136.

[19] Lim, J. S., Cheah, C. B., \& Ramli, M. B. (2019). The setting behavior, mechanical properties and drying shrinkage of ternary blended concrete containing granite quarry dust and processed steel slag aggregate. Construction and Building Materials, 215, 447-461.

[20] Anwar, M. and Emarah, D.A., 2019. Pore structure of concrete containing ternary cementitious blends. Results in Materials, 1, p.100019.

[21] Nagaratnam, B. H., Mannan, M. A., Rahman, M. E., Mirasa, A. K., Richardson, A., \& Nabinejad, O. (2019). Strength and microstructural characteristics of palm oil fuel ash and fly ash as binary and ternary blends in Self-Compacting concrete. Construction and Building Materials, 202, 103-120.

[22] Jung, S. H., Choi, Y. C., \& Choi, S. (2017). Use of ternary blended concrete to mitigate thermal cracking in massive concrete structures-A field feasibility and monitoring case study. Construction and Building Materials, 137, 208-215.

[23] C. Nagaraja, Dr. J.K. Dattatreya and Dr. K.P.Shivananda (2017), A Comparative Study of The Retrofitting of Reinforced Concrete Beams Under Flexural Loading, International Journal of Civil Engineering and Technology, 8(9), 2017, pp. 449-461.

[24] Munagala Sreenivasulu Reddy and Suvarna P. (2016), A Detailed Study on Reclaimed Asphalt Pavement in Pavement Quality Cement Concrete. International Journal of Civil Engineering and Technology, 7(5), 2016, pp.382 -392.

[25] Dr. D. V. Prasada Rao and M. Pavan Kumar (2014), A Study on Influence of Fly Ash and Nano- Silica on Strength Properties of Concrete, International Journal of Advanced Research in Engineering and Technology (IJARET), Volume 5, Issue 7, July (2014), pp. 76-84. 